Tjalling C. Koopmans Research Institute

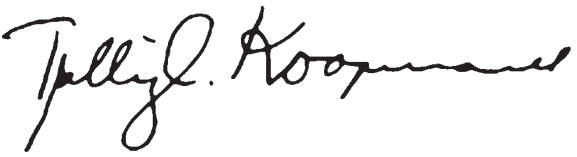

Discussion Paper Series nr: 09-17

\title{
An extended gravity model with substitution applied to international trade
}

Jacob A. Bikker 


\title{
Tjalling C. Koopmans Research Institute Utrecht School of Economics \\ Utrecht University
}

Janskerkhof 12

3512 BL Utrecht

The Netherlands

telephone $\quad+31302539800$

fax +31302537373

website www.koopmansinstitute.uu.nl

The Tjalling C. Koopmans Institute is the research institute and research school of Utrecht School of Economics.

It was founded in 2003, and named after Professor Tjalling C. Koopmans, Dutch-born Nobel Prize laureate in economics of 1975.

In the discussion papers series the Koopmans Institute publishes results of ongoing research for early dissemination of research results, and to enhance discussion with colleagues.

Please send any comments and suggestions on the Koopmans institute, or this series to J.M.vanDort@uu.nl

ontwerp voorblad: WRIK Utrecht

\author{
How to reach the authors \\ Jacob A. Bikker \\ De Nederlandse Bank (DNB) \\ Supervisory Policy Division \\ Strategy Department \\ P.O. Box 98 \\ 1000 AB Amsterdam \\ The Netherlands \\ E-mail: J.A.Bikker@DNB.nl \\ Utrecht University \\ Utrecht School of Economics \\ Janskerkhof 12 \\ 3512 BL Utrecht \\ The Netherlands.
}

Please direct all correspondence to the first author.

This paper can be downloaded at: http://

www.uu.nl/rebo/economie/discussionpapers 


\title{
An extended gravity model with substitution applied to international trade
}

\author{
Jacob A. Bikker \\ Supervisory Policy Division, Strategy Department \\ De Nederlandse Bank \\ Utrecht School of Economics \\ Utrecht University
}

July 2009

\begin{abstract}
The traditional gravity model has been applied many times to international trade flows, especially in order to analyze trade creation and trade diversion. However, there are two fundamental objections to the model: it cannot describe substitutions between flows and it lacks a cogent theoretical foundation. A newly developed model, the Extended Gravity Model (EGM), overcomes these objections. The model shares characteristics of the models of Bergstrand (1985), Andersen and Van Wincoop (2003), and Redding and Scott (2003). An empirical test on a world-wide sample of 19 thousand 2005 trade flows strongly rejects the gravity model in favour of the EGM. The empirical analysis also shows that the gravity model widely overestimates the influence of the determinants of international trade, which is due to strong substitution between trade flows, reducing the initial (gravity model) effects. Substitution determines both trade creation and trade diversion. The EGM encompasses several models originating in regional economics and can be applied usefully to a wide set of subjects.
\end{abstract}

Keywords: bilateral trade, imports, exports, spatial allocation, trade creation, trade diversion, distance, market access, supplier access, multilateral resistance terms, remoteness indices.

JEL classification: F1, R12.

\section{Acknowledgements}

The author is grateful to an unkown referee, Gert-Jan Linders and other participants of the Workshop 'The gravity equation: or why the world is not flat', Groningen, The Netherlands, October 18-19, 2007, for valuable comments and suggestions and to Jack Bekooij for extensive data support and estimations. This paper enlarges on Bikker (1987), but all empirical results are new. 


\section{Introduction}

For over decades the traditional gravity model has been successfully applied to flows of the most widely varying types, such as migration, flows of buyers to shopping centres, recreational traffic, commuting, patient flows to hospitals and interregional as well as international trade. The model specifies that a flow from origin $i$ to destination $j$ is determined by supply conditions at the origin, by demand conditions at the destination and by stimulating or restraining forces relating to the specific flow between $i$ and $j$. In a context of international trade the traditional gravity model usually has the following form:

$X_{i, j}=\beta_{0} Y_{i}^{\beta_{1}} N_{i}^{\beta_{2}} Y_{j}^{\beta_{3}} N_{j}^{\beta_{4}} D_{i, j}^{\beta_{5}} P_{i, j}^{\beta_{6}}$

where $X_{i, j}$ is the value of trade between countries $i$ and $j, Y_{k}$ and $N_{k}$ are the Gross Domestic Product (GDP) and the size of the population, respectively, of country $k$, and $D_{i, j}$ and $P_{i, j}$ denote the distance between countries $i$ and $j$ and a possible special preference relationship, respectively. The gravity model of bilateral trade has become the workhorse of applied international economics (Eichengreen and Irwin, 1998) and has been used in any number of contexts. ${ }^{1}$ Some authors assume that the size of the population has no impact, thus $\beta_{2}=\beta_{4}=0$, which renders the resemblance to Newton's Law of Gravity even more obvious. ${ }^{2}$

The empirical results obtained with the model have always been judged as very good. Deardorff (1998) argues that the model is sensible, intuitive and hard to avoid as a reduced theoretical model to explain bilateral trade. Yet the gravity model has some serious imperfections. One is the absence of a cogent derivation of the model, based on economic theory. Several authors have tried to provide the model with such a theoretical basis, using models of imperfect competition and product differentiation, notably Anderson (1979), Bergstrand (1985), Helpman and Krugman (1985) and Anderson and Van Wincoop (2003), whereas Deardorff (1998) proves that the model is also consistent with the Heckscher-Ohlin trade theory under perfect competition. However, none of these derivations generates the gravity model exactly as formulated in Equation (1). ${ }^{3}$ This equation could only be approximated under a number of restrictive and unrealistic assumptions, as has been made clear by Bergstrand (1985).

\footnotetext{
${ }^{1}$ Linders (2006) found 200 studies (actually a sample from a much larger set), and provides a selection in his Table 3.1. For an overview, see Anderson and Van Wincoop (2004).

${ }^{2}$ E.g. Tinbergen (1962), Pöyhönen (1963a, 1963b), Pulliainen (1963), Geraci and Prewo (1977), Prewo (1978), Abrams (1980) and Bergstrand (1985).

${ }^{3}$ The most restrictive theoretical model of Anderson, Bergstrand, as well as Helpman and Krugman, is a gravity model with only GDPs as determinants. A less restrictive model has a different functional form (Anderson, Equation (16) or additional determinants (Bergstrand, Equation (14)).
} 
Another imperfection of the gravity model is the absence of substitution between flows. ${ }^{4}$ Existence of substitution can be made plausible by economic integration. For example, the accession of Estonia to the European Union (EU) in 2004 is expected to lead to additional imports by other EU countries of wood, wood products and paper (their major export product) - that is, gross trade creation, $c f$. Balassa (1962). However, EU imports of wood products from other countries may very well decline (somewhat). This decline - trade diversion - is not described by the gravity model. In the analysis of economic integration, for which purpose the gravity model is frequently used, trade creation and trade diversion are important phenomena.

This paper presents an alternative to the gravity model, or rather an extension of it, with substitution between flows. This extended gravity model shows strong similarities to the models of Bergstrand (1985) Anderson and Van Wincoop (2003) and Redding and Scott (2003). It can be derived straightforwardly from supply and demand equations, which provides the model with a theoretical basis. It appears to be a generalisation of the gravity model which permits empirical testing of the assumptions on which the gravity model is based. The extended model generates estimation results which - due to a substitution structure - deviate widely from the gravity model estimates, which underlines the importance of discerning the substitution structure.

The remainder of this paper consists of the following sections. Section 2 gives the derivation of the model, called Extended Gravity Model (EGM), from supply and demand equations. Section 3 compares the EGM with the gravity model, describes its indices of the geo-economic position which establish the model's substitution structure and treats econometric issues. ${ }^{5}$ Section 4 presents estimation results for trade flows between 178 countries in 2005, tests the EGM against the gravity model and interprets the model parameters and the indices of the geo-economic position. Section 5 concludes.

\section{Derivation of the extended gravity model}

The next subsection derives the extended gravity model from a supply and demand system. Alternative derivations from (among other things) constant-elasticity-of-substitution (CES) preference or utility

\footnotetext{
${ }^{4}$ Glejser and Dramais (1969) have attempted to specify a trade model with substitution but, as they admit, their model is not without estimation problems. See also Viaene (1982), whose method, however, becomes very complex when applied to a matrix of trade flows instead of a vector.

${ }^{5}$ Many small, mainly technical problems are more or less ignored in this paper, though they were solved. For a more elaborate introduction of the model, see Bikker and De Vos (1982) or Bikker (1982).
} 
functions are discussed in Section 2.7. The supply and demand system consists of the following four equations:

Supply $\quad E_{i}^{s}=\omega C_{i} p$

$i=1, \ldots, n$

Demand

$$
I_{j}^{d}=\gamma B_{j} q_{j}^{\rho} p_{j}^{\pi}
$$

$j=1, \ldots, m$

Allocation $\quad X_{i, j}^{d} / I_{j}^{d}=p_{i}^{\mu} D_{i, j}^{\varepsilon_{1}} P_{i, j}^{\varepsilon_{2}} / \sum_{k=1}^{n} p_{k}^{\mu} D_{k, j}^{\varepsilon_{1}} P_{k, j}^{\varepsilon_{2}} \quad i \neq j$

Index

$$
q_{j}=\sum_{k=1}^{n} p_{k}^{\mu} D_{k, j}^{\varepsilon_{1}} P_{k, j}^{\varepsilon_{2}}
$$

\subsection{Aggregate supply}

$E_{i}^{s}$ represents the total foreign supply of country $i, C_{i}$, its potential foreign supply and $p_{i}$ the domestic price of its exports, actually a price index, since the export covers a mix of commodities $(\lambda>0)$. The potential foreign supply depends on, inter alia, the productive capacity for tradeable goods, which is proportional to Gross Domestic Product $\left(Y_{i}\right)$ if the ratio between productive capacity for tradeable and non-tradeable goods were equal in all countries. A theoretical micro-economic foundation of this supply equation can be found in Bergstrand (1985), whose Equation (8) is - after summation over $j$ - virtually equal to Equation (3), under a simplifying assumption - absence of price discrimination (i.e. $p_{i, j}=p_{i}$ for all i). Bergstrand uses the same assumption to obtain an applicable model.

\subsection{Aggregate demand}

$I_{j}^{d}$ denotes the total foreign demand of country $j, B_{j}$ its potential foreign demand, ${ }^{6} p_{j}$ the price level of domestically produced tradeable goods $(\pi<0),{ }^{7}$ and $q_{j}$ an index indicating the attractiveness of the whole commodity mix offered by all the exporting countries together $(\rho>0)$. This index varies per country because of the different distances between the importing and exporting countries. It also depends on the foreign export prices, and functions in Equation (4) as a foreign price in the traditional import equation, see Stern et al. (1976).

\footnotetext{
${ }^{6}$ Potential foreign demand depends among other things on national income $\left(Y_{j}\right)$ as a scale factor.

${ }^{7}$ Equation (4) assumes imperfect substitutability between domestically and foreign-produced tradeable goods.
} 


\subsection{Geographical allocation of demand}

The supply and demand system consists of $n$ markets, one for each exporting country. These markets are separated from one another by distances. On each market $m$ countries act as demanders. The demand from each importing country is distributed over the $n$ markets. The demand from country $j$ for products of country $i$ is $X_{i, j}^{d}$. The share of country $i$ in the total demand of country $j, X_{i, j}^{d} / I_{j}^{d}$, depends on price $p_{i}$ $(\mu<0)$ and on specific factors promoting or hampering trade between $i$ and $j$, such as distance, $D_{i, j},\left(\epsilon_{l}<0\right)$ because of transportation and information costs, etc. and preferential relations, $P_{i, j},\left(\epsilon_{2}>0\right)$ if any (economic unions, ties with former colonies, etc.). This results in:

$X_{i, j}^{d} / I_{j}^{d} \propto p_{i}^{\mu} D_{i, j}^{\varepsilon_{1}} P_{i, j}^{\varepsilon_{2}}$

where $\propto$ denotes 'proportionate to', The shares of Equation (7) must add up to 1, due to the restriction $\sum_{i=1}^{n} X_{i, j}^{d}=I_{j}^{d}$ which is automatically met if $X_{i, j}^{d} / I_{j}^{d}$ is specified as in Equation (5). This equation describes the preference of country $j$ to buy products from country $i$ and has the form of the multinomial logit model, which is widely applied to specify choice processes and is provided with a theoretical foundation by means of a derivation from utility functions, $c f$. Daganzo (1979).

Some or all of the importing and exporting countries may coincide. However, the supply and demand system does not involve domestic supplies and deliveries. So, $X_{j, j}$ may be excluded from Equations (5)-(7) and the summations then read: $k=1, \ldots, n ; k \neq j$. This will also hold for the following equations.

\subsection{Attractiveness index}

The index $q_{j}$ denotes the extent to which producers satisfy consumers of $j, c f$. Daganzo (1979). Equation (4) which contains $q_{j}$ is based on the assumption that the reasons why country $j$ prefers to buy products from country $k$ (see Equation (5)) will also play an important role in deciding how much will be bought (see Equation (4)) - why depending on the attractiveness of each of the various alternatives and how much on the attractiveness of all alternatives together. The index $q_{j}$ can be regarded as a foreign price index, where the weights $D_{i, j}^{\varepsilon_{1}}$ and $P_{i, j}^{\varepsilon_{2}}$ for $k=1, \ldots ., n$ are proxies for transportation costs and lower tariff rates for preferential trading arrangements, respectively. 


\subsection{Bilateral demand}

The bilateral demand equation follows from substitution of (4) and (6) into (5):

$X_{i, j}^{d}=\gamma B_{j} q_{j}^{\rho-1} p_{j}^{\pi} p_{i}^{\mu} D_{i, j}^{\varepsilon_{1}} P_{i, j}^{\varepsilon_{2}}$

A theoretical foundation of this equation is given by Bergstrand (1985). Under the assumption of absence

of price discrimination mentioned above, his Equation (4) is in fact equal to Equation (5'), where $q_{j}^{\phi}+p_{j}^{\vartheta}$ is approximated by $q_{j}^{\eta} p_{j}^{\xi}$.

\subsection{Equilibrium}

In export market $i$ price $p_{i}$ balances total supply and aggregate demand (for each $i$ ):

$E_{i}^{s}=\sum_{l=1}^{m} X_{i, l}^{d}$

The equilibrium prices can be derived from:

$p_{i}=\left[\gamma \omega^{-1} C_{i}^{-1} \sum_{l=1}^{m} q_{l}^{\rho-1} p_{l}^{\pi} B_{l} D_{i, l}^{\varepsilon_{1}} P_{i, l}^{\varepsilon_{2}}\right]^{1 /(\lambda-\mu)}$

Equations (6) and (9) form a simultaneous system: $p_{i}$ depends on $q_{l}$ and $p_{l}$ (note: $l \neq i$ ). and $q_{l}$ on $p_{i}$, et cetera. It can be proven that this system has a unique solution. This unique solution provides the equilibrium prices and, by substitution in the other model equations, the equilibrium values of imports, exports and the index. The equilibrium model obtained in this way cannot be applied empirically in its present form, because the simultaneous set of equilibrium prices $p_{i}$ from Equation (9) and index values $q_{j}$ from Equation (6) can only be calculated from exogenous variables, given the unknown parameters $\pi, \lambda$ and $\mu$. An empirically useful model can be obtained if the unidentified system of prices and indices is rewritten into an identified set of indices $\alpha_{i}$ and $\beta_{j}$. These indices are defined as follows: 


$$
\begin{array}{ll}
\alpha_{i}=\sum_{l=1}^{m} q_{l}^{\rho-1} p_{l}^{\pi} B_{l} D_{i, l}^{\varepsilon_{1}} P_{i, l}^{\varepsilon_{2}} & \left(=p_{i}^{\lambda-\mu} C_{i} \omega / \gamma\right) \\
\beta_{j}=\sum_{k=1}^{n} p_{k}^{\mu} D_{k, j}^{\varepsilon_{1}} P_{k, j}^{\varepsilon_{2}} & \left(=q_{j}\right)
\end{array}
$$

The interpretation of these indices is given in the next section. Replacement of $p_{i}$ and $q_{j}$ with functions of $\alpha_{i}$ and $\beta_{j}$ yields a system that is expressed exclusively in $\alpha_{i}$ and $\beta_{j}$, and no longer in $p_{i}$ and $q_{j \cdot}{ }^{8}$

$\alpha_{i}=\sum_{l=1}^{m} \beta_{l}^{-1} I_{l} D_{i, l}^{\varepsilon_{1}} P_{i, l}^{\varepsilon_{2}}$

$\beta_{j}=\sum_{k=1}^{n} \alpha_{k}^{-1} E_{k} D_{k, j}^{\varepsilon_{1}} P_{k, j}^{\varepsilon_{2}}$

with $I_{j}$ and $E_{i}$ the equilibrium values of $I_{j}^{d}$ and $E_{i}^{s}$. This set is identified because, given $\varepsilon_{l}$ and $\varepsilon_{2}$, it can be calculated (iteratively) with observable variables: $I_{j}, E_{i}, D_{i, j}$ and $P_{i, j}$, while $\varepsilon_{1}$ and $\varepsilon_{2}$ can be estimated without information about $\alpha_{i}$ and $\beta_{j}$, see Equation (22) in Section 3.

The equilibrium model expressed in $\alpha_{i}$ and $\beta_{j}$ is: ${ }^{9}$

$$
\begin{aligned}
& E_{i}=\left(\gamma^{\lambda} \omega^{-\mu} \alpha_{i}^{\lambda} C_{i}^{-\mu}\right)^{1 /(\lambda-\mu)} \\
& I_{j}=\gamma^{1+\pi /(\lambda-\mu)} \beta_{j}^{\rho} B_{j}\left(\alpha_{i}^{\pi} C_{j}^{-1} \omega^{-1}\right)^{1 /(\lambda-\mu)} \\
& X_{i, j}=I_{j} E_{i} D_{i, j}^{\varepsilon_{1}} P_{i, j}^{\varepsilon_{2}} /\left(\gamma \alpha_{i} \beta_{j}\right)
\end{aligned}
$$

The properties of this model are analyzed in Section 3.

\subsection{Alternative theoretical foundations of the extended gravity model}

Anderson and Wincoop (2003), abbreviated to A\&W, derive a comparable EGM from a CES preference function, thereby providing a very elegant micro-economic foundation for that model. The similarity of

\footnotetext{
${ }^{8}$ For the derivations here and further on, see Bikker (1982, p. $27 \mathrm{ff}$ ).

${ }^{9}$ If all countries are included, importing and exporting countries coincide. In that case country $j$ 's own price $p_{j}$ is endogenous and, according to Equation (10), a function of $\alpha_{j}$. If only a subset of countries is considered, some $p_{j}$ are exogenous.
} 
their results to ours becomes clear when the above Equations (11) of the indices $\alpha_{i}$ and $\beta_{j}$ are compared to Equations (10) and (11) of the A\&W price indices $\Pi_{i}$ and $P_{j}$. Note that A\&W end up with two (scaled) price indices for each country, reflecting prices of, respectively, imports and exports. Only under a further symmetric trade barrier assumption (discussed below) and a 'balanced trade' assumption do the two price indices coincide, that is, $\Pi_{i}=P_{i}$ (Anderson, 2009). The symmetric trade barrier assumption, however, is far from trivial, as shown below.

Bergstrand (1985) derives a type of EGM using double constant-elasticity-of-substitution (CES) utility functions for consumers and double constant-elasticity-of-transformation (CET) joint production surfaces for producers. He specifies supply and demand for each trade flow $X_{i j}$, but links their aggregates over $i$ and $j$ to the respective countries' national incomes. Bergstrand's equilibrium model for $X_{i j}$ resembles Equation (14) and the model of A\&W, but deviates in that it uses different substitution elasticities on the foreign and domestic markets.

Redding and Scott (2003) and Redding and Venables (2004) derive an EGM rather comparable to that of $\mathrm{A} \& \mathrm{~W}$ and this paper, using Cobb-Douglas preference and production functions. They define (foreign) market access and and (foreign) supplier access identical to our indices $\alpha_{i}$ and $\beta_{j}$, which can be rewritten in prices and price indices. Their model is more restricted as the exponential parameters of market access, supplier access and distance are all equal to $\sigma-1$ or $1-\sigma$. The 'new economic geography' wage level in their model is a function of these access variables, which in turn depend on prices. This approach has also been applied by Bosker and Garretsen (2009) and Boulhol (2009). ). Behrens et al. (2007) develop a gravity model, which is a simplification of the various models above, as it contains only one set of indices, supplier access, instead of two (ignoring market access). ${ }^{10}$ Similarly, Anderson (1979) presents in Equation (16) a gravity model with market access, ignoring supplier access.

For the application of the gravity model to world trade, the A\&W foundation is most elegant. However, the derivation in Sections 2.1-2.6 above has two advantages. First, it applies to a wider set of applications. Earlier, the EGM has been applied to flows of hospital patients from resident areas to hospitals (Bikker and De Vos, 1992a). Other potential applications are the international trade in single commodities (such as oil), commuter traffic, migration flows, and flows of shoppers to shopping centres, students to schools, tourists to holiday destinations, et cetera. In those cases, origin and destination regions do not coincide,

\footnotetext{
${ }^{10}$ This would be equivalent to imposing $\mu=0$ in Equation (5) and (6), see Bikker (1982, p. 38).
} 
contrary to the symmetry between origin and destination regions commonly found in general international trade. ${ }^{11}$

Second, Sections 2.1-2.6 explain clearly that the attractiveness of a country's trade partners (or 'other countries'), given its geographical location, may differ substantially for its imports and its exports. These sections propose the distinct indices $\alpha_{i}$ and $\beta_{j}$ as measures of the geographical attractiveness of, respectively, exports and imports. A\&W come up with two distinct sets of price indices, defined similarly to these indices, but the two sets of price indices coincide under the symmetry trade barrier assumption. Such symmetry is likely with respect to distances and preferential relations due to economic unions, ties with former colonies, et cetera. International trade between two countries depends also heavily on the correlation between the supply by product types of the exporting country and the demand by product types of the importing country. This applies in particular to commodities. Behrens et.al. (2007) and Bergstrand et al. (2009) stress that trade costs are far from symmetric. Symmetry may also be absent for other omitted variables. This is also evident from the empirical application of the EGM: in 2005, the trade barrier residuals (that is, omitted variables) of the trade flows $X_{i, j}$ and $X_{j, i}$ (that is: $u_{i j}$ and $u_{j i}$ ) have a markedly low correlation at 0.2 , pointing to quite limited symmetry. Particularly in the absence of a variable for the correlation between demanded and supplied goods, this argues for the use of both sets of indices, that is, repudiation of the symmetry trade barrier assumption.

Finally, we notice a few further, though not essential, differences between A\&Ws foundation and the derivation given above. A\&W include demand for and supply to domestic consumption. ${ }^{12}$ This inclusion is essential for their derivation, because their (theoretical) model is based on countries' total demand and total supply. Two remarks are in order. First, inclusion of domestic consumption and production is elegant as substitution may be expected between domestic and foreign demand. For domestic consumption and production it is quite common to distinguish between tradeables and non-tradeables (e.g. Anderson, 1979; Bergstrand, 1985). A\&W assume demand substitution among exporter countries to be the same as substitution between foreign and domestic demand, which is less plausible as the substitution between foreign tradeables and domestic non-tradeables is likely to be close(r) to zero. For that reason, Bergstrand assumes different degrees of substitution between demand from various foreign countries and between foreign and domestic demand. In practice, statistics do not exactly distinguish between domestic tradeables and non-tradeables. For that reason, Section 2.2 excludes domestic tradeables (as empirical

\footnotetext{
11 The symmetric trade barrier assumption does not hold true for the international trade of a commodity with a limited number of supply countries. Furthermore, trade data sets may be incomplete, for instance because some trade flows are reported as zero or are in fact absent.

${ }^{12}$ Note that consumption also includes investment goods.
} 
application goes with practical issues), but includes the price level of domestically produced tradeable goods $\left(p_{j}\right)$ in the demand equation (4) so as to take possible substitution into account. This results in a more complex equilibrium equation of imports (13), deviating from the A\&W equation. ${ }^{13}$

There is a second argument why inclusion of domestic consumption and production, the diagonal elements of the trade matrix, are often excluded in practice, although they may appear elegant in the theoretical derivations. In the gravity model all trade flows depend on the distances between pairs of exporting and importing countries, but, in practice, the specification of the distance between producers and consumers within a country is a thorny issue (e.g. Anderson and Smith, 1999, p. 29, Head and Mayer, 2009). Often no trade costs are assumed, that is, the effect of distance is set at zero $\left(\ln \left(D_{i i}\right)=0\right)$. For a better solution, though somewhat arbitrary, see Equation (15) in Bosker and Garretsen (2009). Behrens et al. (2007, p. 8) raise the problem that explanatory variable $G D P_{i}$ is not exogenous to the dependent variable 'domestic consumption' (or production) $X_{i, i}$. Note that the diagonal elements of matrix X may be either included in or deleted from the derivations in Sections 2.1-2.6 above without any change in the theoretical results, apart from the respective interpretation: in the inclusion implies that total production and consumption are described (in fact, national income), ${ }^{14}$ whereas exclusion means that the model refers to imports and exports only. ${ }^{15}$ Hence, it is not needed here to make a principle choice.

\section{THE EXTENDED GRAVITY MODEL}

For empirical application of the equilibrium model thus obtained, it is necessary to specify the concepts of potential foreign supply, $C_{i}$, and demand, $B_{j}$. Potential foreign supply depends on productive capacity, proxied by Gross National Product, $Y_{i}$, and on market size (approximated by population, $N_{i}$ ). The latter is based on the assumption of economies of scale: the larger $N$ is, the higher is the number of production lines for which the country will meet the minimum market size for efficient market production. The larger $N$, therefore, the larger the domestic market will be in relation to the foreign market, and the smaller the potential foreign supply. Other lines of reasoning for $N_{i}$ in the export equations can be found in Leamer and Stern (1970), Krugman (1979, 1980) and Brada and Mendez (1983), see also Linnemann (1966), Leamer (1974) and Chenery and Syrquin (1975). An alternative explanatory variable is the country's surface area $A_{i}$, which may reflect size, occurrence of mineral resources, and average distance to foreign

\footnotetext{
${ }^{13}$ In the empirical application the import equation is used in its simplified form, see Equation (17) below.

${ }^{14}$ Note that if the EGM described all production and consumption (hence include diagonal elements), $\pi$, i.e. the elasticity of the (competing) price level of domestically produced tradeable goods, would equal 0 in Equation (4).

${ }^{15}$ A third option would be to include only (domestic) tradeable goods in the diagonal elements.
} 
countries. In this paper, areas are used in variants only. The variables $Y_{j}$ and $N_{j}$ determine potential foreign demand, using the same arguments as were applied to potential foreign supply.

Thus, the following equations are obtained.

$I_{j}=\delta_{0} \beta_{j}^{\delta_{1}^{*}} Y_{j}^{\delta_{2}} N_{j}^{\delta_{3}} \alpha_{j}^{\delta_{4}}$

$E_{i}=\gamma_{0} \alpha_{i}^{\gamma_{1}} Y_{i}^{\gamma_{2}} N_{i}^{\gamma_{3}}$

Note that Equations (12)-(13) do not impose restrictions on the coefficients in Equations (15)-(16). In our empirical application the variable $\alpha_{i}$ in Equation (15) is deleted (or: $\beta_{j}^{\delta_{1}^{*}} \alpha_{j}^{\delta_{4}}$ is approximated by $\beta_{j}^{\delta_{1}}$ ). Due to the observed rough symmetry between imports and exports $\left(E_{k} \approx I_{k}\right)$, there appears to be a strong correlation between $\alpha_{i}$ and $\beta_{j}$ (in 2005: 0.92), which may cause multicollinearity. Not only in the empirical section but, for convenience, in this section as well, Equation (15) is replaced by:

$I_{j}=\delta_{0} \beta_{j}^{\delta_{1}} Y_{j}^{\delta_{2}} N_{j}^{\delta_{3}}$

Substitution of Equations (16) and (17) into (14) produces:

$X_{i, j}=\gamma_{0}^{\prime} \alpha_{i}^{y_{1}-1} Y_{i}^{\gamma_{2}} N_{i}^{\gamma_{3}} \beta_{j}^{\delta_{1}-1} Y_{j}^{\delta_{2}} N_{j}^{\delta_{3}} D_{i, j}^{\varepsilon_{1}} P_{i, j}^{\varepsilon_{2}}$

\subsection{Comparison of the Extended Gravity Model to the traditional gravity model.}

This equation clearly shows that $\gamma_{1}=\delta_{l}=1$ corresponds to the standard gravity model, $c f$. Equation (1). The theoretical meaning of these restrictions becomes clear after comparison of Equations (15) and (16) with (13) and (12): $\delta_{1}=\rho$ and $\gamma_{I}=\lambda /(\lambda-\mu)$. The restrictions in 'background' parameters are $\rho=1$ and $\mu=0$ or $\lambda=\infty$, respectively. The interpretation of these parameters follows easily from the rewritten supply and demand system:

$E_{i}^{s}=\omega C_{i} p_{i}^{\lambda}$

$X_{i, j}^{d}=\gamma B_{j} q_{j}^{\rho-1} p_{j}^{\pi} p_{i}^{\mu} D_{i, j}^{\varepsilon_{1}} P_{i, j}^{\varepsilon_{2}}$ 
So, $\rho=1$ means inelasticity of the demand for $q_{j}$, the extent to which producers satisfy consumers of country $j$ or, phrased differently, the attractiveness for country $j$ of the goods of all other exporting countries together. The extreme case of perfectly elastic supply, $\lambda=\infty$, relates to another market system where equilibrium is met not by price adjustment but by quantity adjustment. As this is not a likely market system for aggregated trade flows, the relevant restriction is $\mu=0$, meaning no cross-price elasticy in the demand equation. Therefore, the hypotheses which produce the traditional gravity model are demand inelasticity to the attractiveness index $q$ and cross-price inelasticity of demand. These hypotheses will be tested in Section 4.

\subsection{Indices of the geo-economic position}

The indices $\alpha_{i}$ and $\beta_{j}$ play a pivotal role in the extended gravity model. They are interpreted as follows: $\beta_{j}$ is an index of the attractiveness to country $j$ of the goods offered by the exporting countries, weighted by the distance (see Section 2), or - in other words - a mean distance between country $j$ and the exporting countries, weighted by the attractiveness to country $j$ of the goods offered; an index of the geo-economic position. Because of the symmetry in model structure (with respect to import and export countries), $\alpha_{i}$ can be called the attractiveness of country $i$ 's sales market, weighted by the distance to the importing countries. One may also consider Equation (10) in which $\alpha_{i}$ depends upon the weighted potential foreign demand (mainly purchasing power) of the importing countries, $B_{j}$. The occurrence of $\beta_{j}^{-1}$ in the terms of index $\alpha_{i}$ can be explained as follows: country $j$ will be the more attractive to country $i$ to sell to as the latter suffers less from competition by other exporting countries. As noted above, $\alpha_{i}$ and $\beta_{j}$ are highly correlated. Equations (16) and (17) show how exports and imports each depend upon the geo-economic indices concerned. It is to be expected that $\gamma_{1}>0$ and $\delta_{1}>0$. Other names for these indices or closely related indices are (foreign) market access and (foreign) supplier access (Redding and Scott, 2003), inward and outward multilateral resistance terms (Anderson and Van Wincoop, 2003; Anderson, 2009), remoteness indices, balancing factors (Wilson, 1967), and spatial competition (Behrens et al., 2007).

\subsection{Substitution structure}

The coefficients $1-\gamma_{1}$ and $1-\delta_{1}$ are interpreted as the degree of substitution between flows of similar origin and similar destination, respectively. To explain that, we imagine that, owing to economic integration, trade preference between two countries, say $i_{0}$ and $j_{0}$ doubles, thus $P_{i_{0}, j_{0}}^{\varepsilon_{2}}$ becomes 2 instead of 
1, see Equation (18). The terms of $\alpha_{i_{0}}$ and $\beta_{j_{0}}$, which correspond to the trade flow between $i_{0}$ and $j_{0}$ also contain the factor $P_{i_{0}, j_{0}}^{\varepsilon_{2}}$. If $\gamma_{1}=\delta_{1}=0$, total exports of country $i_{0}$ and total imports of country $j_{0}-c f$. Equations (16) and (17) - do not change: additional trade between $i_{0}$ and $j_{0}$ is entirely at the expense of other trade flows of similar origin or similar destination - thus trade diversion without (net) trade creation, or full substitution. ${ }^{16}$ By contrast, if $\gamma_{1}=\delta_{1}=1-$ the traditional gravity model case - Equation (18) shows ${ }^{17}$ that there will be no substitution at all - trade creation without trade diversion. Doubling of $X_{i_{0}, j_{0}}$ say from $\mathrm{x}$ to $2 \mathrm{x}$, will, if $\gamma_{1}=\delta_{1}=1$, lead to more exports from country $i_{0}$ to a value of $\mathrm{x}$ and more imports by country $j_{0}$ to the same amount. Thus we conclude that $1-\gamma_{1}$ and $1-\delta_{l}$ reflect the degree of substitution between export flows and import flows, respectively. If $\gamma_{1}$ and $\delta_{1}$ exceed 1 , complementarity between flows will outweigh substitution.

\subsection{Econometric issues}

To apply the EGM empirically, disturbance terms are added to the logarithms of Equations (16)-(18). These terms must meet the restrictions to which the model is also subjected, i.e. flows $X_{i, j}$ should add up over the rows to imports $\left(I_{j}\right)$ and over the columns to exports $\left(E_{i}\right)$. At the same time this means that the sum of the imports equals the sum of the exports: $\Sigma_{j} I_{j}=\Sigma_{i} E_{i}$. The latter restriction implies that stochastically exports and imports cannot be specified independently. A simple solution of this problem is to specify one of the two equations in terms of deviation from the level, and to let the other one determine the level. For estimation results, predictions, etc., it does not matter which equation is selected. We choose the following specification:

$$
\begin{aligned}
& \ln E_{i}=\gamma_{0}^{\prime}+\gamma_{1} \ln \alpha_{i}+\gamma_{2} \ln Y_{i}+\gamma_{3} \ln N_{i}+v_{i} \\
& \ln \widetilde{I}_{j}=\delta_{1} \ln \widetilde{\beta}_{j}+\delta_{2} \ln \widetilde{Y}_{j}+\delta_{3} \ln \widetilde{N}_{j}+\widetilde{w}_{j}
\end{aligned}
$$

where $\sim$ denotes 'in deviation from the arithmetic mean'. In Equation (20), the transformation $\sim$ refers to, respectively, $\ln I_{i}, \ln \beta_{j}, \ln Y_{j}, \ln N_{j}$ and $w_{j}$ (and hence not to $I_{i}, \beta_{j}$, etc.). Both equations are conditional upon calculated values of $\alpha_{i}$ and $\beta_{j}$. To keep the estimation procedure simple, $E_{i}$ and $I_{j}$ in the formulae of $\alpha_{i}$ and $\beta_{j}$ - see Equation (11) - are replaced by estimations of the corresponding expectations. The indices are

\footnotetext{
${ }^{16}$ It can be proved that the EGM with $\gamma_{1}=0$ and/or $\delta_{l}=0$ corresponds to one of the so-called constrained gravity models originating in regional economics, $c f$. Wilson (1967).

${ }^{17}$ As found earlier, these restrictions relate to demand inelasticity to the attractiveness index $q$ and cross price inelasticity of demand.
} 
then (re)defined as follows - where, for convenience, the same names are employed for these nonstochastic indices:

$\alpha_{i}=\sum_{l=1}^{m} \beta_{l}^{\delta_{1}-1} Y_{l}^{\delta_{2}} N_{l}^{\delta_{3}} D_{i, l}^{\varepsilon_{1}} P_{i, l}^{\varepsilon_{2}}$

$\beta_{j}=\sum_{k=1}^{n} \alpha_{k}^{\gamma_{1}-1} Y_{k}^{\gamma_{2}} N_{k}^{\gamma_{3}} D_{k, j}^{\varepsilon_{1}} P_{k, j}^{\varepsilon_{2}}$

Under one restriction, say $\prod_{j=1}^{m} \beta_{j}=1$, this iterative system is unique for given parameter values.

The restrictions on $X_{i, j}$ imply that, after taking logarithms, the arithmetic means over $i$ and, subsequently, over $j$ can be subtracted from Equation (18) without losing any statistical information. This eliminates all the terms which depend solely on $i$ or solely on $j$ :

$\ln \widetilde{\widetilde{X}}_{i, j}=\varepsilon_{1} \ln \widetilde{\widetilde{D}}_{i, j}+\varepsilon_{2} \ln \widetilde{\widetilde{P}}_{i, j}^{\varepsilon_{2}}+\widetilde{\widetilde{u}}_{i, j}$

in which $\approx$ denotes 'in deviation from the arithmetic means over $i$ and, subsequently, over $j$ '. In Equation (22), the transformation $\approx$ refers to, respectively, $\ln X_{i, j}, \ln D_{i, j}, \ln P_{i, j}$ and $u_{i, j}$. Equation (22) only reflects the geographical distribution or a (gravity) model with two sets of fixed effects for import and export countries (compare to Feenstra, 2002, 2004). Statistically Equation (22) corresponds to the traditional analysis-of-variance model. Equations (19)-(22) add up to the Extended Gravity Model (EGM), which will be applied to international trade in the next section. Note that Equations (19), (20) and (22) successively determine $n,(m-1)$ and $(n-1)(m-1)$ degrees of freedom, therefore together exactly $n m$.

The three model equations can be estimated with OLS. The estimation procedure is as follows:

(1) first $\varepsilon_{1}$ and $\varepsilon_{2}$ are estimated with OLS: $\hat{\varepsilon}_{1}$ and $\hat{\varepsilon}_{2} ;{ }^{18}$

(2) $\alpha$ and $\beta$ are calculated iteratively given $\hat{\varepsilon}_{1}$ and $\hat{\varepsilon}_{2}$, given initial values for the gammas and deltas, e.g. from the estimation of a gravity model. Moreover, $\alpha_{i}$ will then be conditional on the values of $\beta_{j}$ and vice versa;

(3) Equations (19) and (20) are estimated, given values of $\alpha$ and $\beta$, with which new OLS estimates of the gammas and deltas are obtained;

(4) Steps (2) and (3) are repeated until given convergence criteria are met.

\footnotetext{
${ }^{18}$ OLS estimates are Best Linear Unbiased, as is shown for a special case by Teekens and Jansen (1977). This follows from the law of Aitken, see Theil (1971).
} 
If the disturbance terms are normally distributed, the total likelihood function can be formulated and therefore the most likely estimates can be calculated. These estimates may depart slightly from the OLS estimates, since through the indices in Equation (21) the imports and exports equations may contain information about the estimates of $\varepsilon_{1}$ and $\varepsilon_{2}$ from the allocation Equation (22). Maximum likelihood estimates can be calculated with a numerical estimation procedure.

\section{Estimation results}

This section applies both the traditional gravity model and the EGM to international aggregated trade flows between 178 countries. As diagonal elements relate to domestic supplies and deliveries, they have not been included here, so there are in principle 178 x 177 individual trade flows. Part of the flows $(12,156)$ have been recorded as zero due to rounding or to actual absence of trade, leaving 19,350 nonzero flows. ${ }^{19}$ The figures date back to 2005. Information about the data used is given in Appendix A.

Table 1 shows estimation results of the common gravity model and our extended version of it. A number of preference variables have been added to the model, which will be explained below. We present results of two variants of the EGM, the EGM with standard $\alpha$ and $\beta$, as introduced above, and the EGM based on $\alpha$ and $\beta$ which include the allocation residuals $\widetilde{\widetilde{u}}_{i, j}$ :

$\alpha_{i}(\widetilde{\widetilde{u}})=\sum_{l=1}^{m} \beta_{l}^{\delta_{1}-1} Y_{l}^{\delta_{2}} N_{l}^{\delta_{3}} D_{i, l}^{\varepsilon_{1}} P_{i, l}^{\varepsilon_{2}} \exp \left(\widetilde{\widetilde{u}}_{i, l}\right)$

$\beta_{j}(\widetilde{\widetilde{u}})=\sum_{k=1}^{n} \alpha_{k}^{\gamma_{1}-1} Y_{k}^{\gamma_{2}} N_{k}^{\gamma_{3}} D_{k, j}^{\varepsilon_{1}} P_{k, j}^{\varepsilon_{2}} \exp \left(\widetilde{\widetilde{u}}_{k, j}\right)$

\footnotetext{
${ }^{19}$ Bikker and De Vos (1992b) aim at solving estimation bias due to zero trade flows.
} 
Table 1. Estimation results of the traditional and extended gravity model (2005)

\begin{tabular}{|c|c|c|c|c|c|c|c|}
\hline & \multirow[t]{2}{*}{$\begin{array}{l}\text { Para- } \\
\text { meters }\end{array}$} & \multicolumn{2}{|c|}{$\begin{array}{l}\text { Traditional gravity } \\
\text { model }\end{array}$} & \multicolumn{2}{|c|}{$\begin{array}{l}\text { EGM (standard } \alpha \\
\text { and } \beta)\end{array}$} & \multicolumn{2}{|c|}{$\begin{array}{l}\text { EGM }(\alpha \text { and } \beta \text { with } \\
\left.\text { residuals } \widetilde{\tilde{u}}_{i, j}\right)\end{array}$} \\
\hline & & Coeff. & t-values & Coeff. & $t$-values & Coeff. & t-values \\
\hline & & \multicolumn{6}{|c|}{ Export model } \\
\hline Intercept & $\gamma_{0}^{\prime}$ & -10.62 & $(-41.5)$ & -2.377 & $(-7.5)$ & -3.369 & $(-8.2)$ \\
\hline Alpha (market access) & $\gamma_{1}$ & & & 0.106 & $(1.5)$ & 0.197 & $(3.8)$ \\
\hline GDP & $\gamma_{2}$ & 1.25 & $(113.4)$ & 1.101 & $(28.5)$ & 1.148 & $(32.4)$ \\
\hline Population & $\gamma_{3}$ & -0.04 & $(-3.1)$ & -0.122 & $(-2.9)$ & -0.119 & $(-3.0)$ \\
\hline Number of observations & & & & 178 & & 178 & \\
\hline \multirow[t]{2}{*}{ R-squared, adjusted } & & & & 90.4 & & 91.0 & \\
\hline & & & & \multicolumn{2}{|c|}{ Import model } & & \\
\hline Beta (supplier access) & $\delta_{1}$ & & & 0.230 & $(4.1)$ & 0.121 & $(2.0)$ \\
\hline GDP & $\delta_{2}$ & 0.89 & $(80.7)$ & 0.908 & $(33.5)$ & 0.944 & $(36.2)$ \\
\hline Population & $\delta_{3}$ & 0.02 & $(2.0)$ & -0.086 & $(-2.8)$ & -0.110 & $(-3.5)$ \\
\hline Number of observations & & & & 178 & & 178 & \\
\hline \multirow[t]{2}{*}{ R-squared, adjusted } & & & & 93.4 & & 92.9 & \\
\hline & & & & \multicolumn{2}{|c|}{ Allocation model } & & \\
\hline Distance & $\varepsilon_{l}$ & -1.30 & $(-55.4)$ & -1.699 & $(-71.3)$ & & \\
\hline Neighbours & $\varepsilon_{2}$ & 0.99 & $(8.1)$ & 0.568 & $(5.4)$ & & \\
\hline Common language off. & $\varepsilon_{3}$ & 0.36 & (4.4) & 0.641 & $(8.3)$ & & \\
\hline Common language. eth. & $\varepsilon_{4}$ & 0.65 & $(8.3)$ & 0.156 & $(2.0)$ & & \\
\hline Former colonial relations & $\varepsilon_{5}$ & 0.60 & $(4.5)$ & 0.738 & $(6.0)$ & & \\
\hline Commonwealth & $\varepsilon_{6}$ & 1.07 & $(13.2)$ & 0.448 & $(5.2)$ & & \\
\hline French territorial areas & $\varepsilon_{7}$ & 0.66 & $(2.8)$ & 1.244 & $(5.8)$ & & \\
\hline Communist past & $\varepsilon_{8}$ & 0.15 & (1.6) & 0.933 & $(9.8)$ & & \\
\hline Soviet Union & $\varepsilon_{9}$ & 2.16 & $(10.6)$ & 2.411 & (12.7) & & \\
\hline Warsaw Pact & $\varepsilon_{10}$ & 0.02 & $(0.1)$ & 0.345 & $(1.2)$ & & \\
\hline EU6 & $\varepsilon_{11}$ & -0.94 & $(-2.1)$ & -2.813 & $(-7.3)$ & & \\
\hline EU9-6 & $\varepsilon_{12}$ & -0.88 & $(-9.9)$ & -1.080 & $(-1.3)$ & & \\
\hline EU12-9 & $\varepsilon_{13}$ & -0.23 & $(-0.2)$ & -0.315 & $(-0.4)$ & & \\
\hline EU15-12 & $\varepsilon_{14}$ & 0.11 & $(-0.1)$ & -0.629 & $(-0.8)$ & & \\
\hline EU25-15 & $\varepsilon_{15}$ & 0.69 & $(2.6)$ & 0.514 & $(2.2)$ & & \\
\hline Number of observations & & 19,350 & & 19,350 & & & \\
\hline R-squared, adjusted & & 63.5 & & 33.0 & & & \\
\hline
\end{tabular}

The latter can be seen as more precise, because they include also the information about the geographical allocation as contained in the omitted variables, such as the correlation between the composition in terms of products between supply of the export country and demand of the import country. Bosker and Garretsen (2009) show how extreme sensitive the (market access) indices are with respect to the specification of the trade costs model (or geographical allocation model) when applied in a new-economic-geography wage function. Inclusion of the allocation errors would solve that problem to a large extent. Estimates of the models including also the surface area of importing and exporting countries can be found in Appendix B. The parameter estimates of both the traditional and the extended gravity model seem to correspond fairly reasonably to what has been found by other authors. However, the interpretation of the extended gravity 
model will appear to be quite different. Before examining the parameter estimates in detail, we will discuss the major difference between the gravity model and the EGM.

\subsection{Comparison of the gravity model with the EGM}

The gravity model is a special case of the EGM. The models are equal if two sets of restrictions are imposed on the latter. The first set concerns the substitution between flows, which is lacking in the gravity model, owing to the two restrictions $\gamma_{1}=\delta_{1}=1$. The second set regards the error structure. Comparison of Equations (19), (20) and (22) with (14) shows that the EGM has an error with a variance components structure: $\widetilde{\widetilde{u}}_{i, j}+\widetilde{w}_{j}+v_{i}$. This error structure reduces to an ordinary one $\left(u_{i, j}\right)$ only if a special relation between the standard deviations $\sigma_{v}, \sigma_{w}$ and $\sigma_{u}$ holds: ${ }^{20}$

$m \sigma_{v}=n \sigma_{w}=\sigma_{u}$

A Wald test on the two restrictions $\gamma_{1}=\delta_{1}=1$ (that is, a gravity model with a variance components error structure) makes clear that these restrictions (and thus the traditional gravity model) are rejected in favour of the EGM with a well-nigh maximum conviction. Earlier calculations have revealed that the - from an economic point of view - less crucial restrictions on the standard deviations of the errors terms are rejected with even more confidence, supporting the rejection of the traditional gravity model (Bikker, 1987).

The EGM has also been compared with the gravity model in a second way. This way is inspired by the fact that interest in total imports and exports per country is often greater than in individual trade flows. When the country aggregates of the gravity model are compared to those of the EGM, the gravity model again proves to be strongly defeated by the EGM - for their standard deviations of total exports and total imports residuals appear to be well over 50\% higher than those of the EGM. Moreover, the gravity model rather heavily overestimates the actual totals, but this could be due in part to problems of interpreting the constant in a log-linear model, see Teekens and Koerts (1972).

\footnotetext{
${ }^{20}$ Some elements of the analysis become a little more complex if observations are lacking, as is the case here. One element is the restriction (24) which in this empirical application is actually formulated somewhat differently. Another is the reduction of Equation (18) to (22): the transformation $\approx$ now requires more calculations. A third relates to the Jacobian required to transform the dependent variables of the EGM into those of the gravity model. In all cases the problems are purely technical and have been fully solved, see Bikker (1982).
} 


\subsection{Interpretation of the EGM parameter estimates}

On the face of it, most parameter values of the gravity model and of the EGM do not differ much, especially not in the equations for imports and exports, whereas it is exactly here that some differences might be expected, because of the diverging coefficients of the indices ( 0.106 versus 1 and 0.230 versus 1 , see Table 1, standard $\alpha$ and $\beta$ ). Closer examination, however, shows that the EGM parameters clearly have a different meaning from those of the gravity model. This is because each explanatory variable also occurs in both indices and therefore affects the modelled trade flow along three channels. Therefore, the overall effect is not immediately apparent. Of course, the effect of a variable can always be determined with a model simulation. However, it is also possible to interpret the parameter estimates analytically. For it can be demonstrated that the effect of (changes in) $Y$ or $N$ from the export equation on $X_{i, j}$ equals $\gamma_{2}$ or $\gamma_{3}$, respectively, each multiplied by:

$\delta_{1} /\left(\gamma_{1}+\delta_{1}-\gamma_{1} \delta_{1}\right)$

that is, provided there is an equal proportional change in $Y$ or $N$ in all exporting countries. We call the coefficients multiplied by (25) overall-effect elasticities. They are immediately comparable with the parameters $\beta_{1}$ and $\beta_{2}$ from the gravity model. The overall effect elasticities of the import equation (apart from $\delta_{1}$ itself) and the distribution model are obtained analogously by multiplying the corresponding parameters with, respectively:

$\gamma_{1} /\left(\gamma_{1}+\delta_{1}-\gamma_{1} \delta_{1}\right) \quad$ and $\quad \gamma_{1} \delta_{l} /\left(\gamma_{1}+\delta_{1}-\gamma_{1} \delta_{1}\right)$

The overall effect elasticities are shown in Column 3 of Table 2. The effects on trade flows of GDP and population of the imports and exports model have been added together because in this empirical example importing and exporting countries coincide, so that a change in e.g. all GDPs will affect the modelled trade flow along the import side as well as the export side. Remarkably, nearly all overall effects of the EGM are much smaller than those of the gravity model. Owing to substitution, part of the initial effects leak away. This effect is similar to the lower 'border effect' between the US and Canada measured by the EGM of Anderson and Van Wincoop (2003), including the multilateral resistance terms, compared to the traditional gravity model of McCallum (1995), see also Behrens et al. (2007, p. 8).

If we recalculate the elasticities in Table 2 on the EGM with $\alpha$ and $\beta$ with residuals $\widetilde{\widetilde{u}}_{i, j}$ instead of the standard EGM $\alpha$ and $\beta$, we obtain largely identical results (see third and fourth row in Table 2). This 
illustrates that different values of the coefficients of $\alpha$ and $\beta$ (that is, $\gamma_{1}$ and $\delta_{l}$ ) should not be considered separately but together.

Table 2. Elasticities between explanatory variables and trade flows (standard $\alpha$ and $\beta ; 2005$ )

\begin{tabular}{|c|c|c|c|c|}
\hline \multirow[b]{3}{*}{ Column } & \multirow{2}{*}{$\begin{array}{l}\text { Traditional } \\
\text { gravity model }\end{array}$} & \multicolumn{2}{|l|}{ EGM } & \multirow[t]{2}{*}{3 as $\%$ of 1} \\
\hline & & Initial effect & Overall effect ${ }^{a}$ & \\
\hline & 1 & 2 & 3 & 4 \\
\hline & & \multicolumn{2}{|l|}{ standard $\alpha$ and $\beta$} & \multirow{3}{*}{0.524} \\
\hline GDP (import \& export) & 2.140 & 2.010 & 1.122 & \\
\hline Population (import \& export) & -0.020 & -0.210 & -0.119 & \\
\hline & & \multicolumn{2}{|c|}{$\alpha$ and $\beta$ with residuals } & \multirow{3}{*}{0.515} \\
\hline GDP (import \& export) & 2.140 & 2.090 & 1.101 & \\
\hline Population (import \& export) & -0.020 & -0.230 & -0.123 & \\
\hline Distance & -1.300 & -1.700 & -0.137 & 0.105 \\
\hline Neighbours & 0.990 & 0.570 & 0.046 & 0.046 \\
\hline Common language, official & 0.360 & 0.640 & 0.051 & 0.143 \\
\hline Common language, ethnic & 0.650 & 0.160 & 0.013 & 0.020 \\
\hline Former colonial relations & 0.600 & 0.740 & 0.059 & 0.099 \\
\hline Commonwealth & 1.070 & 0.450 & 0.036 & 0.034 \\
\hline French territorial areas & 0.660 & 1.240 & 0.100 & 0.151 \\
\hline Communist past & 0.150 & 0.930 & 0.075 & 0.498 \\
\hline Soviet Union & 2.160 & 2.410 & 0.194 & 0.090 \\
\hline Warsaw Pact & 0.020 & 0.350 & 0.028 & 1.407 \\
\hline EU6 & -0.940 & -2.810 & -0.226 & 0.240 \\
\hline EU9-6 & -0.880 & -1.080 & -0.087 & 0.099 \\
\hline EU12-9 & -0.230 & -0.320 & -0.026 & 0.112 \\
\hline EU15-12 & 0.110 & -0.630 & -0.051 & -0.460 \\
\hline EU25-15 & 0.690 & 0.510 & 0.041 & 0.059 \\
\hline
\end{tabular}

${ }^{\mathrm{a}}$ For the allocation based on standard $\alpha$ and $\beta ;{ }^{\mathrm{b}}$ Quotient is high due to nominator value close to zero.

\subsection{Individual parameter estimates}

The estimated coefficients of $\alpha_{i}$ and $\beta_{j}$ of the standard EGM are $0.106\left(\gamma_{l}\right)$ and $0.230\left(\delta_{l}\right)$, respectively. They prove that the EGM provides a better description of international trade than the gravity model, as $\gamma_{1}$ $<1$ and $\delta_{1}<1$. On the other hand, they show that countries' exports and imports depend significantly on the geo-economic position, because $\gamma_{1}>0$ and $\delta_{1}>0$ holds jointly. As is made clear in Section $3,1-\gamma_{1}$ and $1-\delta_{l}$ denote the degree of substitution between flows from exporting country $i$ and between flows to importing country $j$, respectively. The observed value of $1-\gamma_{1}$ is 0.894 . Additional exports stemming from new trade possibilities due to e.g. economic integration, newly introduced products or the opening of a new trade route (e.g. the Panama canal), ${ }^{21}$ go with a decrease in export flows to less attractive destinations by $89 \%$ of the additional sales (i.e. gross trade creation). Similarly, additional imports due to new

\footnotetext{
${ }^{21}$ Or the re-opening of the Suez canal in 1975 after the closure in 1956, or the newly navigable North-West Passage (North of Canada) or, in the near future, the North-East Passage (North of Russia).
} 
attractive import possibilities go with a 77\% decrease in competitive import flows. Apparently, ignoring substitution would generate disastrous model forecasts.

The EGM coefficients of the GDPs of import and export countries suggest that a $1 \%$ growth of the world economy leads to a somewhat more than proportional increase in international trade flows of $1.22 \%$, see Column 3 of Table 2. This corresponds to past observations. This contrasts, however, with the more than 'quadratic' increase in trade suggested by the gravity model, see Column 1. Remarkably, exports outgrow GDP ( $\gamma_{2}$ is 1.10$)$, whereas import grow lags behind GDP grow $\left(\delta_{2}=0.91\right)$. The size of the population reflects scale economies: large countries are more autarkic. Their effects are in line with expectations, but the population coefficients are small compared to the values observed in the past. Apparently, the optimal scale becomes larger over time: even large countries cannot afford to produce for the domestic market alone.

Distance is the major allocation variable. Its coefficient in the EGM approaches the parameter in Newton's law. The coefficient is higher than observed in the past, as also found in a survey by Linders (2006). Our value is at the highest end of the observed estimates. This may reflect a world-wide convergence of prices, so that transportation costs count more heavily (Estevadeordal et al. (2003) and Anderson and Van Wincoop, 2004). Further, the allocation model includes the following preferential dummy variables, which reflect the intangible barriers to trade related to cultural differences, institutional conditions and differences other than those embodied by mere distance (Obstfeld and Rogoff, 2000; Deardorff 2004): whether or not two countries are contiguous, share a common official language, have a common language due to ethnic composition of the population, have ever had a colonial link, are both members of the Commonwealth or the Francophone 'Communauté Financière Africaine' (CFA), are both former communist countries, are both former members of the Soviet Union or the former Warsaw Pact, or, finally, are both EU Member States, with a further distinction by membership of the 6, 9, 12, 15, or 25 Member Community. For instance, EU9-6 refers to (additional) trade of Denmark, Ireland and the UK with the first six EU Member States as well as their mutual trade. Most preferential coefficients are in line with expectations, that is, have positive signs; many are more or less consistently significant. Many excolonial preferences are weaker than observed in the past. Apparently, ex-colonial ties have worn thinner in the course of time. A remarkable exception in the expected effects is EU membership, where the older cohorts have negative rather than positive signs. ${ }^{22}$ This might be due to measurement errors: even a minor

\footnotetext{
${ }^{22}$ Intra-EU trade is larger than the trade between the other countries in Western Europe, as shown by Aitken (1973). Abrams (1980) and Bergstrand (1985), who used European trade flow figures only. Negative EU coefficients point to a level of EU trade which is nevertheless lower than the level of world trade, after correction for the size of the countries $(Y$ and $N)$, for distances, etc.
} 
error in the determination of the - relatively small - distances between EU countries would greatly affect the EU coefficients, as the EU countries lie closely together (see Head and Mayer, 2009). Comparisons over time could reveal the true EU impact on international trade. ${ }^{23}$ The R-squares make clear that we are able to explain only a minor part of the variation in the allocation $\left(\mathrm{R}^{2}=33.0\right)$, compared to that in the imports $\left(\mathrm{R}^{2}=92.9\right)$ and exports $\left(\mathrm{R}^{2}=91.0\right)$.

\subsection{The indices of the geo-economic position}

The index $\alpha_{i}$ can be called the attractiveness of country $i$ 's sales market, weighted by the distances to the respective importing countries, whereas $\beta_{j}$ is an index of the attractiveness to country $j$ of the goods offered by the respective exporting countries, again weighted by distance. Table 3 presents regional means for both indices, with and without allocation residuals, all expressed in deviation from their geometric world-wide mean. We first discuss the indices without residuals, reflecting best the geographical position of countries. The location of the European countries clearly is a favourable one - with, in economic terms, many countries with a large economy situated closely together. This holds even more for Central and Eastern Europe and the former Soviet Union (former Soviet Union members have strong mutual preferences), which lie near Western Europe. North American countries benefit from the USA with its gigantic economy, while the USA itself lies less favourably. South America, Africa and, particularly, Oceania, have more isolated locations, whereas the Middle East and the Rest of Asia take intermediate positions.

The allocation residual $\widetilde{\widetilde{u}}_{i, j}$ reflects mainly the correlation between the composition in terms of products between the supply of country $i$ and the demand of country $j$. If they are included in the indices, the alpha's of countries with sought-after products rise. Oil producing countries in the Middle East and countries producing raw material in Africa become more attractive, whereas regions with less mineral resources, such as Europe and Asia lose attraction. The position of importing countries is affected less strongly.

\footnotetext{
${ }^{23}$ Comparison of earlier estimates for 1974 and 1959 - before the EU could make any considerable contribution towards economic integration - shows that the relative preference for other EU countries over 1959-1974 rose by $76 \%$ (Bikker, 1987). In other words, it is not the level of the EU dummy, but the change therein that provides quantitative information about economic integration. However, such a shift has not been observed over 1975-2005.
} 
Table 3. Geo-economic trade positions of exports $(\alpha)$ and imports $(\beta)$ per region

\begin{tabular}{|c|c|c|c|c|}
\hline & \multicolumn{2}{|c|}{ Without residuals $\widetilde{\widetilde{u}}_{i, j}$} & \multicolumn{2}{|c|}{ With residuals $\widetilde{\widetilde{u}}_{i, j}$} \\
\hline & Alpha's & Beta's & Alpha's & Beta's \\
\hline Western Europe & 1.86 & 1.73 & 0.40 & 1.36 \\
\hline Central and Eastern Europe ${ }^{a}$ & 3.23 & 2.27 & 1.67 & 2.89 \\
\hline Former Soviet Union & 4.46 & 2.70 & 1.20 & 1.96 \\
\hline North and Central America & 0.98 & 1.59 & 0.81 & 1.14 \\
\hline South America & 0.51 & 0.63 & 0.43 & 1.00 \\
\hline Middle East & 1.13 & 0.80 & 2.82 & 0.91 \\
\hline Rest of Asia & 0.93 & 1.17 & 0.56 & 0.60 \\
\hline Oceania & 0.32 & 0.47 & 1.22 & 0.50 \\
\hline North-Western Africa & 0.60 & 0.57 & 1.77 & 0.74 \\
\hline South-Eastern Africa & 0.38 & 0.37 & 1.05 & 0.56 \\
\hline
\end{tabular}

${ }^{\text {a }}$ Excluding the former Soviet Union Member countries.

Explanation: The indices are from the EGM without area and are expressed in deviation from their world-wide geometric mean.

\section{CONCLUSIONS}

The Extended Gravity Model (EGM) proves to be a useful extension of the traditional gravity model. A test of 2005 figures on international trade flows quite convincingly rejects the gravity model in favour of the more generalised EGM. Apparently, EGMs substitution structure, which does not preclude a relatively simple estimation procedure, is a much more realistic model for international trade. In general, the degree of substitution between trade flows appears to be around $80 \%$ or more. This structure, in principle, allows for an analysis of economic integration in terms of trade diversion and trade creation. The EGM leads to conclusions regarding the effect of the determinants of trade flows, which deviate clearly from those reached by means of the gravity model: the traditional gravity model strongly overestimates the effects of changes in determinants. In addition, the EGM provides index values of the geo-economic trade position for all countries concerned, both of the attractiveness of a country's sales market, weighted by the distances to the respective importing countries, and of the attractiveness to each country of the goods offered by the respective exporting countries, again weighted by distance.

The EGM can be applied usefully to a wide variety of subjects, see e.g. Bikker and De Vos (1992a) on patient flows to hospitals. Apart from the log-linear regression model, the EGM also encompasses the production-constrained, the attraction-constrained and the so called doubly-constrained gravity models originating in regional economics, $c f$. Wilson (1967), and of the analysis-of-variance model, see Cesario (1973) and Wansbeek (1977). From a statistical point of view, the EGM has well-defined properties. Empirical application requires more calculations than in the case of the traditional gravity model. However, the applications show clearly that the effort pays off. 


\section{References}

Abrams, R.K.: International Trade Flows under Flexible Exchange Rates, Economic Review, Federal Reserve Bank of Kansas City, 1980, 3-10.

Aitken, N.D.: The Effect of the EEC and EFTA on European Trade: A Temporal Cross-Section Analysis. American Economic Review 63 (1973), 881-892.

Anderson, J.E.: A Theoretical Foundation for the Gravity Equation, American Economic Review 69 (1979), 106-116.

Anderson, M.A., and S.L.S. Smith, Canadian provinces in would trade: engagement and detachment, Canadian Journal of Economics 32 (1999), 22-38.

Anderson, J.E. and Van Wincoop, E., Gravity with gravitas: a solution to the border puzzle, American Economic Review 93 (2003), 170-192.

Anderson J.E. and Van Wincoop, E., Trade costs, Journal of Economic Literature 42 (2004), 691-751.

Anderson, J.E., The Incidence of Gravity in General Equilibrium, In: Brakman, S., and P.A.G. van Bergeijk (eds), The Gravity Model in International Trade: Advances and Applications, Cambridge University Press, 2009, Chapter 2, (forthcoming).

Balassa, B.: The Theory of Economic Integration, London: Allen and Unwin, 1962.

Behrens, K., C. Ertur and W. Koch, Dual gravity: using spatial econometrics to control for multilateral resistance, CORE Discussion Paper 2007/59, 2007.

Bergstrand, J.H.: The Gravity Equation in International Trade: Some Microeconomic Foundations and Empirical Evidence. Review of Economics and Statistics 67 (1985), 471-481.

Bergstrand, J.H., P. Egger and M. Larch, Approximating General Equilibrium Impacts of Trade Liberalization using the Gravity Equation, In: Brakman, S., and P.A.G. van Bergeijk (eds), The Gravity Model in International Trade: Advances and Applications, Cambridge University Press, 2009, Chapter 3, (forthcoming).

Bikker, J.A.: Vraag-aanbodmodellen voor stelsels van geografisch gespreide markten. toegepast op de internationale handel en op ziekenhuisopnamen in Noord-Nederland (In Dutch; Supply-demand Models for Systems of Geographically Dispersed Markets. with Applications to International Trade Flows and Hospital Admissions in the North of the Netherlands). Amsterdam: Free University Publishing Company, 1982.

Bikker, J.A., An international trade flow model with substitution: an extension of the gravity model, Kyklos 40 (1987), 315-337.

Bikker, J.A. and De Vos, A.F.: Interdependent Multiplicative Models for Allocation and Aggregates: A Generalization of Gravity Models, Research Paper 80, Actuarial Science and Econometrics Department, Amsterdam: Free University, 1982. 
Bikker, J.A., and De Vos, A.F., A regional supply and demand model for inpatient hospital care, Environment and Planning A 24 (1992a), 1097-1116.

Bikker, J.A., and De Vos, A.F., An international trade flow model with zero observations: an extension of the Tobit model, Cahiers Economiques de Bruxelles 135 (1992b), 379-404.

Bosker, E.M., and H. Garretsen, Trade costs, market access and economic geography: Why the empirical specification of trade costs matters, In: Brakman, S., and P.A.G. van Bergeijk (eds), The Gravity Model in International Trade: Advances and Applications, Cambridge University Press, 2009, Chapter 6, (forthcoming).

Boulhol, H., The Contribution of Economic Geography to GDP Per Capita, In: Brakman, S., and P.A.G. van Bergeijk (eds), The Gravity Model in International Trade: Advances and Applications, Cambridge University Press, 2009, Chapter 11 (forthcoming).

Cesario, F.J.: A Generalized Trip Distribution Model. Journal of Regional Science 13 (1973), 223-247.

Chenery, H. and Syrquin, M.: Patterns of Development, 1950-1970, World Bank, Oxford University Press, 1975.

Daganzo, C.: Multinomial Probit, the Theory and its Application to Demand Forecasting, New York: Academic Press, 1979.

Deardorff, A.V., Determinants of bilateral trade: does gravity work in a neoclassical world?, in : J. Frenkel (ed.), The Regionalization of the World Economy, 7-28, Chicago, University of Chicago Press, 1998.

Deardorff, A.V., Local comparative advantage: trade costs and the pattern of trade, Research Seminar in International Economics Discussion Paper, University of Michican nr. 500, Ann Arbor, 2004.

Eichengreen, B., and Irwin, D.A., The role of history in bilateral trade flows, in: J.A. Frankel (ed.), The Regionalization of the World Economy, 33-57, Chicago, University of Chicago Press, 1998.

Estevadeordal, A., Frantz, B., and Taylor, A.M., The rise and fall of world trade, 1870-1939, Quarterly Journal of Economics 68 (2003), 359-408.

Feenstra, R.E., Border effects and the gravity equation: consistent methods for estimation, Scottish Journal of Political Economy 49 (2002), 491-506.

Feenstra, R.E., Advanced International Trade: Theory and Evidence, Princeton and Oxford, NJ: Princeton University Press, 2004.

Geraci, V.J. and Prewo, W.: Bilateral Trade Flows and Transport Costs. Review of Economics and Statistics 59 (1977), 67-74.

Glejser, H. and Dramais, A.: A Gravity Model of Interdependent Equations to Estimate Flow Creation and Diversion. Journal of Regional Science 9 (1969), 439-449. 
Head, K., and Mayer, T. L'effet frontière: une mesure de l'intégration économique, Economie et Prévision 152-153 (2002), 71-92.

Head, K., and Mayer, T., Illusory border effects: distance mismeasurement inflates estimates of home bias in trade, In: Brakman, S., and P.A.G. van Bergeijk (eds), The Gravity Model in International Trade: Advances and Applications, Cambridge University Press, 2009, Chapter 5, (forthcoming).

Helpman, E. and Krugman, P.R.: Market Structure and Foreign Trade: Increasing Returns, Imperfect Competition, and the International Economy, Cambridge (USA), 1985.

Krugman, P.R.: Increasing Returns. Monopolistic Competition and International Trade, Journal of International Economics 9 (1979), 469-479.

Krugman, P.R.: Scale Economies, Product Differentiation and the Pattern of Trade, American Economic Review 70 (1980), 950-959.

Leamer, E.E. and Stern, R.M.: Quantitative International Economics. Boston: Allyn and Bacon, 1970.

Leamer, E.E.: Nominal Tariff Averages with Estimated Weights. Southern Economic Journal 41 (1974), 34-45.

Linders, G.J.M., Intangible barriers to trade; the impact of institutions, culture and distance on pattern of trade, Tinbergen Institute Research Series nr. 371, Tinbergen Institute, 2006.

Linnemann, H.: An Econometric Analysis of International Trade Flows. Amsterdam: North-Holland Publishing Company, 1966.

McCallum, J., National borders matter: Canada-US regional trade patterns, American Economic Review 85 (1995), 615-623.

Obstfeld, M., and Rogoff, K., The six major puzzles in international macro-economics: is there a common cause?, In: NBER Macro-economics Annual 15, 339-390, Cambridge, MA: the MIT Press, 2000.

Pelzman, J.: Trade Creation and Trade Diversion in the Council of Mutual Economic Assistance. 1954-70. American Economic Review 67 (1977), 713-722.

Pölyhönen, P.: A tentative model for the volume of trade between countries, Welwirtschaftliches Archiv 90 (1963a), 93-100.

Pölyhönen, P.: Toward a General Theory of International Trade. Economiska Samfundets Tidskrift 16 (1963b), 69-77.

Prewo, W.: Determinants of the Trade Pattern among OECD Countries from 1958 to 1974, Jahrbücher für Nationalökonomie und Statistik 193 (1978), 341-358.

Pulliainen, K.: A World Trade Study: An Econometric Model of the Pattern of the Commodity Flows of International Trade in 1948-60. Economiska Samfundets Tijdskrift 16 (1963), 78-91

Redding, S. and P.K. Scott, Distance, Skill Deepening and Development: Will Peripheral countries Ever Get Rich?, Journal of Development Economics 72 (2003), 515-541. 
Redding, S. and A.J. Venables, Economic Geography and International Inequality, Journal of International Economics 62 (2004), 53-82.

Stern, R.M.: Francis J. and Schumacher. B.: Price Elasticities in International Trade, London and Basingstoke, 1976.

Teekens, R. and Koerts, J.: Some Statistical Implications of the Log Transformation of Multiplicative Models, Econometrica 40 (1972), 793-813.

Teekens, R. and Jansen, R.: A Note on the Estimation of a Multiplicative Allocation Model. Research Report 7703, Econometric Institute, Rotterdam: Erasmus University, 1977.

Theil, H.: Principles of Econometrics. New York: John Wiley and Sons, 1971.

Tinbergen, J.: Shaping the World Economy. New York: 20th Century Fund, 1962.

Viaene, J.M.: A Customs Union between Spain and the EEC, European Economic Review 18 (1982), 345368.

Wansbeek, T.: Least Squares Estimation of Trip Distribution Parameters: A Note. Transportation Research 11 (1977), 429-431.

Wilson, A.G.: A Statistical Theory of Spatial Distributed Models. Transportation Research 1 (1967), 253269. 


\section{Appendix A. EXPLANATION ON THE DATA USED}

The trade flow figures are from 'Direction of Trade Statistics (DOTS)' of the International Monetary Fund (IMF) and date back to 2005. They solely concern trade of goods, as figures of flows of services were not available. The trade flows are recorded in the exporting countries and are expressed in free-on-board (fob) prices, so that the data are not affected by transportation costs. We also applied our models on imports data, yielding fully similar results. The trade data are expressed in millions of US dollars. In 2005, the DOTS database includes 181 countries. Three countries, Turkmenistan, Serbia and Montenegro and the Democratic Republic of Congo, were dropped as they could not be linked to the distances from the 'Centre d'Etudes Prospectives et d'Information Internationales' (CEPII; see below), so that 178 countries remain. A large number of the flows (39\%) are reported as missing or zero, and are either really zero or rounded to zero. The rounding thresholds vary and depend on the statistics of the exporting country.

The GDP and population figures are from the International Financial Statistics (IFS) of the IMF. GDP data in national currencies are converted to millions of US dollars, using IFS exchanges rates. The GDP figures are nominal ones, being a scaling factor of the nominal trade flows. Population figures are expressed in millions. Missing values of GDP and population are replaced by observations from the 2007 edition of the CIA World Fact book. ${ }^{24}$ Surface area of land, exclusive of inland water, is expressed in ten squared kilometres and dates back from 2002 (source: UNSTAT ${ }^{25}$ ).

Distances between countries are expressed in kilometres and stem from CEPII. ${ }^{26}$ Distances are weighted measures, based on all principal cities of the respective countries in order to assess the geographic distribution of population inside each nation. Hence, the distance between two countries is based on bilateral distances between the largest cities of those two countries, those inter-city distances being weighted by the share of the city in the overall country's population. Latitudes, longitudes and population data of main agglomerations of all countries available are from www.world-gazetteer.com. The distance formula used is a generalized mean of city-to-city bilateral distances developed by Head and Mayer (2002, 2009), where we takes the arithmetic mean and not the harmonic means.

CEPII provides also dummy variables indicating whether two countries are contiguous, share a common language, have had a common colonizer after 1945, have ever had a colonial link, have had a colonial relationship after 1945, are currently in a colonial relationship (the dist_cepii.xls file). There are two

\footnotetext{
${ }^{24}$ Source: https://www.cia.gov/library/publications/the-world-factbook/index.html.

${ }^{25}$ Source: FAOSTAT (Rome), http://unstats.un.org/unsd/cdb/cdb_series_xrxx.asp?series_code=3700.

${ }^{26}$ Source: http://www.cepii.fr/anglaisgraph/bdd/distances.htm.
} 
common languages dummies, the first one based on the fact that two countries share a common official language, and the other set to one if a language is spoken by at least $9 \%$ of the population in both countries. Trying to give a precise definition of a colonial relationship is obviously a difficult task. Colonization is here a fairly general term that we use to describe a relationship between two countries, independently of their level of development, in which one has governed the other over a long period of time and has contributed to the current state of its institutions. Other dummy variables for Common Wealth Membership, CFA Membership, formerly communistic countries, former Members of the Soviet Union, former Members of the Warsaw Pact, Membership of the EU6, 9, 12, 15, or 25 are from various sources (e.g. Wikipedia).

\section{Appendix B ESTIMATES OF VARIANTS ON THE MAIN MODELS}

Table A.1. Estimation results of the traditional gravity model including surface areas (2005)

\begin{tabular}{lrr}
\hline & Coefficients & \multicolumn{1}{c}{ t-values } \\
\hline Intercept & -9.08 & $(-32.4)$ \\
GDP export country & 1.24 & $(112.7)$ \\
Population export country & 0.06 & $(3.3)$ \\
Area export country & -0.09 & $(-8.0)$ \\
GDP import country & 0.87 & $(79.6)$ \\
Population import country & 0.16 & $(9.0)$ \\
Area import country & -0.13 & $(-10.8)$ \\
Distance & -1.28 & $(-54.5)$ \\
Neighbours & 1.09 & $(9.0)$ \\
Common language, official & 0.44 & $(5.4)$ \\
Common language, ethnic & 0.58 & $(7.3)$ \\
Former colony relations & 0.58 & $(4.4)$ \\
Commonwealth & 1.00 & $(12.3)$ \\
French territorial areas & 0.79 & $(3.4)$ \\
Communist past & 0.17 & $(1.8)$ \\
Soviet Union & 2.25 & $(11.1)$ \\
Warsaw Pact & 0.03 & $(0.1)$ \\
EU6 & -1.17 & $(-2.6)$ \\
EU9-6 & -0.94 & $(-1.0)$ \\
EU12-9 & -0.26 & $(-0.3)$ \\
EU15-12 & 0.08 & $(0.1)$ \\
EU25-15 & 0.63 & $(2.4)$ \\
Number of observations & 19,350 & \\
R-squared. adjusted & 63.8 & \\
\hline
\end{tabular}


Table A.2. Estimation results of the imports and exports models including surface area (2005)

\begin{tabular}{lrrrr}
\hline & \multicolumn{2}{c}{ EGM without residuals $\tilde{\widetilde{u}}_{i, j}$} & \multicolumn{3}{c}{ EGM with residuals $\widetilde{\widetilde{u}}_{i, j}$} \\
\cline { 2 - 5 } Export model & Coefficients & t-values & Coefficients & t-values \\
\hline Intercept & -3.10 & $(-7.0)$ & -3.60 & $(-7.7)$ \\
GDP & 1.10 & $(28.8)$ & 1.15 & $(32.4)$ \\
Population & -0.22 & $(-3.8)$ & -0.18 & $(-3.1)$ \\
Area & 0.10 & $(2.5)$ & 0.06 & $(1.5)$ \\
Alpha (market access) & 0.14 & $(2.0)$ & 0.18 & $(3.4)$ \\
Number of observations & 178 & & 178 & \\
R-squared, adjusted & 90.7 & & 91.1 & \\
Import model & & & & \\
GDP & 0.91 & $(34.4)$ & 0.93 & $(36.7)$ \\
Population & 0.00 & $(0.1)$ & 0.01 & $(0.1)$ \\
Area & -0.09 & $(-3.4)$ & -0.10 & $(-3.9)$ \\
Beta (supplier access) & 0.19 & $(3.5)$ & 0.13 & $(2.3)$ \\
Number of observations & 178 & & 178 & \\
R-squared, adjusted & 93.7 & & 93.4 & \\
\hline
\end{tabular}

Table A.3. Regional geo-economic trade positions of the EGM including surface areas

\begin{tabular}{|c|c|c|c|c|}
\hline & \multicolumn{2}{|c|}{ Without residuals $\widetilde{\widetilde{u}}_{i, j}$} & \multicolumn{2}{|c|}{ With residuals $\widetilde{\widetilde{u}}_{i, j}$} \\
\hline & Alpha's & Beta's & Alpha's & Beta's \\
\hline Western Europe & 1.97 & 1.62 & 0.42 & 1.32 \\
\hline Central and Eastern Europe $^{\mathrm{a}}$ & 3.42 & 2.10 & 1.85 & 2.72 \\
\hline Former Soviet Union & 3.78 & 3.32 & 1.21 & 1.95 \\
\hline North and Central America & 0.91 & 1.69 & 0.80 & 1.20 \\
\hline South America & 0.46 & 0.69 & 0.41 & 1.06 \\
\hline Middle East & 1.16 & 0.78 & 2.91 & 0.89 \\
\hline Rest of Asia & 1.21 & 0.89 & 0.60 & 0.58 \\
\hline Oceania & 0.29 & 0.51 & 0.98 & 0.55 \\
\hline North-Western Africa & 0.60 & 0.57 & 1.79 & 0.72 \\
\hline South-Eastern Africa & 0.38 & 0.37 & 1.06 & 0.55 \\
\hline
\end{tabular}

${ }^{\text {a }}$ Exclusive of the Former Soviet Union.

Explanation: The indices are expressed in deviation from their geometric world-wide mean. 